\title{
Intelligent Control of Vibration Energy Harvesting System
}

\author{
Nizar N. Almajdy*1, Rabee' H. Thejel' ${ }^{2}$, Ramzi S. Ali ${ }^{1}$ \\ ${ }^{1}$ Electrical Engineering Department, University of Basrah(UOB), Basrah, Iraq \\ ${ }^{2}$ Southern Technical University (STU), Basrah, Iraq
}

\author{
Correspondence \\ *Nizar Nasser Almajdy \\ Electrical Engineering Department, \\ University of Basrah, Basrah, Iraq. \\ Email: almohanad78@yahool.com
}

\begin{abstract}
The Intelligent Control of Vibration Energy Harvesting system is presented in this paper. The harvesting systems use a mechanical vibration to generate electrical energy in a suitable form for use. Proportional-Integrated-derivative controller and Fuzzy Logic controller have been suggested; their parameters are optimized using a new heuristic algorithm, the Camel Traveling Algorithm(CTA). The proposed circuit Simulink model was constructed in Matlab facilities, and the model was tested under various operating conditions. The results of the simulation using the CTA was compared with two other methods.

KEYWORDS: Energy harvesting, piezoelectric, PID controller, Fuzzy controller, parameters optimization, Camel traveling algorithm.
\end{abstract}

\section{INTRODUCTION}

The harvested energy from the environment represents an active area for researchers. The goal of energy harvesting is the attempt to optimize the use of available natural resources as well as the energy that resulted from human movement or equipment. The process of converting ambient energy is done by using particular energy forms converters depending on nature around. Power received from Solar, the energy of winds, the variety of temperature degrees, and the energy resulted from mechanical vibration represent energy forms in the environment.

Many researches in the field of energy harvesting have been developed, such as the topics of energy harvester, which was based on a piezoelectric element (PZT), which is reviewed by Sodano [1]. The harvester efficiency was estimated, and also the electrical circuit and power storage form are discussed. The microsystems and wireless sensors supplied by energy harvester from mechanical vibration results from host structures and household goods into electrical energy were introduced by Beeby [2]. Multiple energy sources were compared, and the harvester, which converts the vibration energy was focused, by Pereyma [3]. Also, self-powering sensors which are used for on-site real-time. These sensors are powered by energy harvester based on PZT. The physical and geometrical configurations of these harvesters were reviewed by Anton and Sodano [4]. Priya has introduced a review of energy harvester based on
PZT and discussed the efficiency and the choosing of PZT transducers [5]. The latest advances of the PZT energy harvester were reviewed by Chennault [6]. Control vibration through use in energy harvesting applications, by Rafique [7]. Pedersen discussed the low frequency and voltage vibration harvester [8]. Later, Wang and Inman introduced a search for several control strategies for vibration damping and the energy which is harvested by using piezo-ceramics [9]. Optimal control for efficient vibration harvester is introduced by Hosseinloo, Long $\mathrm{Vu}$, and Turitsyn[10]. High flexible multifunctional wing uses embedded piezoelectric-materials for control, and the energy to be harvested from vibration was studied by Tsushima and Weihua Su [11].

The energy results from mechanical vibration can be changed to electrical power using three conversion techniques, which are classified as electromagnetic, electrostatic, and piezoelectric [12]. In this work, a piezoelectric element will be considered.

In this paper, the whole system Simulink model is constructed, which is consists of the piezo array as an energy source when exposed with an external force; this means that the output voltage is not constant. A DC-DC converter will be connected to the output of the energy harvester in an attempt to keep the voltage constant to the desired value. The controller will be designed to determine the duty cycle that drives the electronic switch of the converter (MOSFET) triggering to 
maintain constant output. PD like fuzzy + I controller and PID controller are planned for this purpose. The controller parameters $\mathrm{Kp}, \mathrm{Ki}$, and $\mathrm{Kd}$, are optimized with the Camel-travelingalgorithm (CTA). Finally, the modeling execution results are compared with one using the trial and error method for the Fuzzy controller and one using the Nichols Ziegler-method for PID.

\section{ENERGY HARVESTER MODELING AND SIMULATION}

The mathematical modeling of the vibration energy harvester using a piezoelectric element will be presented, and the Simulink model will be given

\section{A. Piezoelectric model}

Piezoelectricity can be defined as the electrical charge accrued in some materials like crystals, ceramics, and some polymer. It is a response to mechanical strain or mechanical stress [13].

The piezoelectric property represents the electromechanical coupling relation [14]. The constitutive equations which form this relation are [15]:

$$
\begin{gathered}
S=S^{E} T+d E \\
D=d T+\varepsilon E
\end{gathered}
$$

where,

$\boldsymbol{T}=$ Stress in MPa, $\boldsymbol{S}=$ Strain, $\boldsymbol{E}=$ Electric field in $\mathrm{V} / \mathrm{m}, \boldsymbol{D}=$ Electrical displacement in $\mathrm{C} / \mathrm{m}^{2}, \boldsymbol{s}^{\boldsymbol{E}}=$ Elastic compliance in $\mathrm{m}^{2} / \mathrm{N}, \boldsymbol{d}=$ Piezoelectric charge constant in $\mathrm{C} / \mathrm{N}$ or $\mathrm{m} / \mathrm{V}, \boldsymbol{C}=$ Permittivity in $\mathrm{F} / \mathrm{m}$.

The state-space of the piezoelectric element at no load can be derived with the help of "(1)" and "(2)" as given in [16]:

$$
\begin{aligned}
& {\left[\begin{array}{l}
\dot{y_{1}} \\
\dot{y_{2}} \\
\dot{y_{3}}
\end{array}\right]=\left[\begin{array}{ccc}
0 & 0 & \left(d A / m s^{E} h\right) / C_{p} \\
0 & 0 & 1 \\
-d A / m s^{E} h & -\left(k p+k_{m}\right) / m & -c / m
\end{array}\right]\left[\begin{array}{l}
y_{1} \\
y_{2} \\
y_{3}
\end{array}\right]+} \\
& {\left[\begin{array}{c}
0 \\
0 \\
F_{e} / m
\end{array}\right]}
\end{aligned}
$$

where,

$$
\left[\begin{array}{l}
y_{1} \\
y_{2} \\
y_{3}
\end{array}\right]=\left[\begin{array}{l}
V \\
z \\
\dot{z}
\end{array}\right],
$$

$\mathrm{V}=$ Produced voltage in volt,

$\mathrm{z}=$ Displacement in $\mathrm{mm}$.

Fig. 1 shows the Simulink model of the piezoelectric element can be given according to (3).

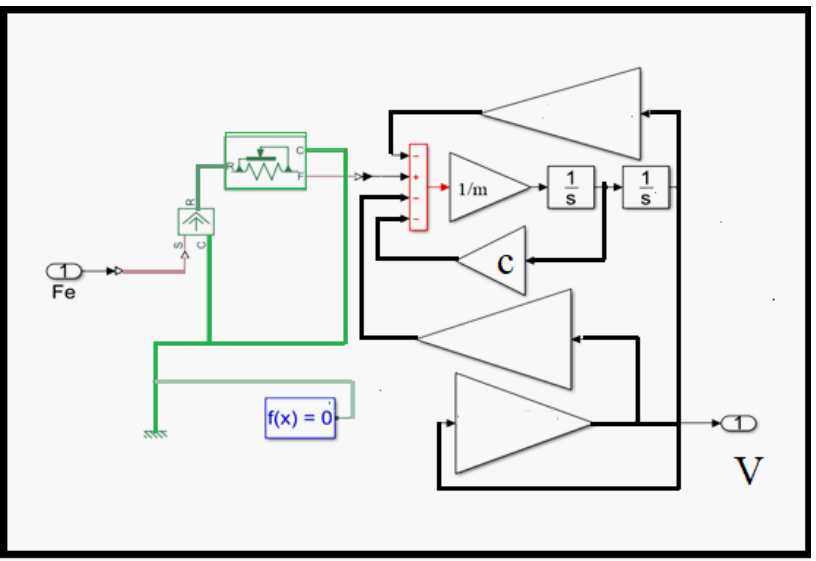

Fig. 1: Piezoelectric element Simulink model.

\section{B. The proposed circuit}

The proposed circuit is shown in Fig. 2. It consists of a piezo array as an ac voltage source followed by a rectification circuit consists of a full-wave bridge diode rectifier and RC filter to enhance dc smoothing and also to play as a voltage capture circuit. This de voltage is supplied to the DC-DC buckboost converter to get the desired voltage value. The controller drives this converter by controlling the duty cycle applied to the switching device. Battery or storage device can be connected to the power store.

The proposed model circuit can be explained in more details as follows:

\section{1) Piezo array and rectification circuit}

The Piezo array consists of three strings; each string has four piezo elements connected in series. These strings can be connected throw a full-wave rectifier and $\mathrm{RC}$ filter for $\mathrm{AC}$ to DC rectification, which represents $\mathrm{SEH}$ (standard energy harvester)[9]. The bridge rectifier also can be used for isolating the strings from each other's to prevent the circulating current. Fig.3 shows the piezo array Simulink model.

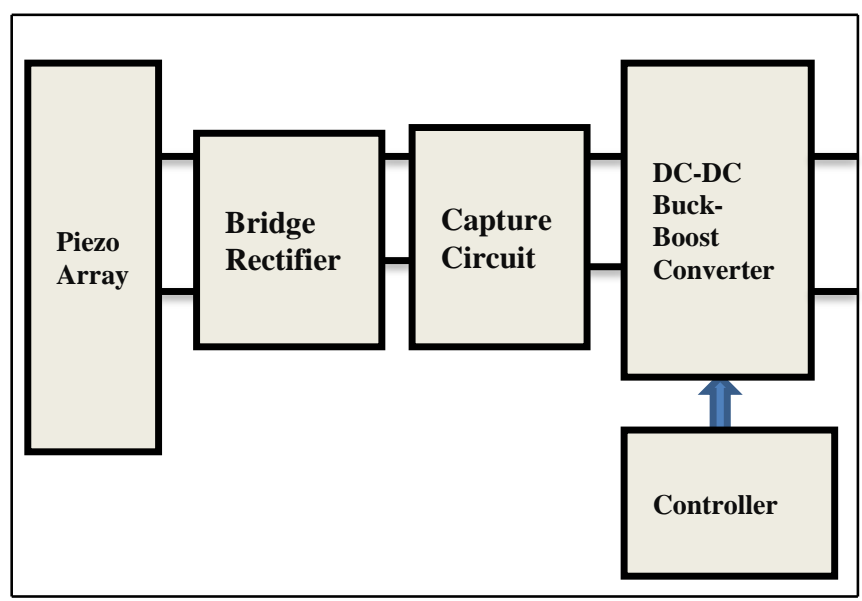

Fig. 2: The proposed circuit topology. 


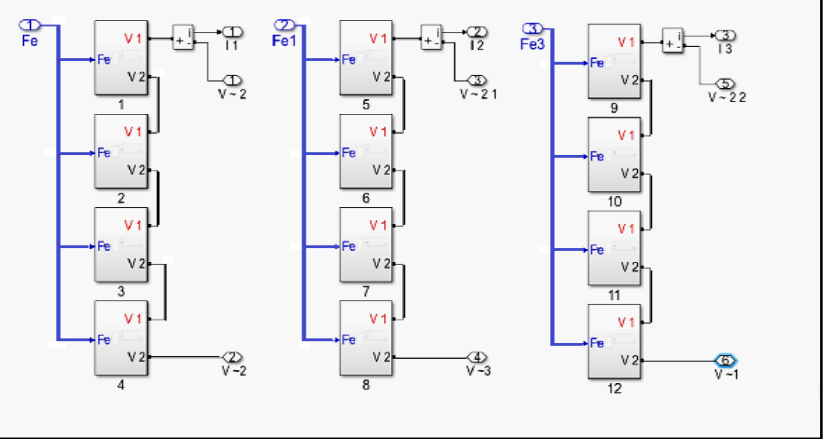

Fig. 3: Piezo array Simulink model.

2) DC - to - DC Buck-Boost Converter

The converter is designed and simulated to keep the output voltage constant. Inductor and capacitor's (see Fig. 4) values are calculated to ensure the converter is working in continuous conduction mode [17].

Where,

where,

$$
\begin{gathered}
\operatorname{Lmin} \geq\left(\left(1-D_{r}\right) 2 R / 2 f\right. \\
C=\left(D r V_{o}\right) /\left(R f \Delta V_{o}\right)
\end{gathered}
$$

$\boldsymbol{L}_{\min }=$ Minimum value of the inductance,

$\boldsymbol{D}_{\boldsymbol{r}}=$ Duty ratio,

$\boldsymbol{C}=$ Capacitance,

$\boldsymbol{R}=$ Load resistance,

$\boldsymbol{V}_{\boldsymbol{o}}=$ Output voltage,

$\Delta \boldsymbol{V}_{\boldsymbol{o}}=$ Output voltage ripple

And, $\boldsymbol{f}=$ Switching frequency.

The Simulink model of the converter is shown in Fig. 5

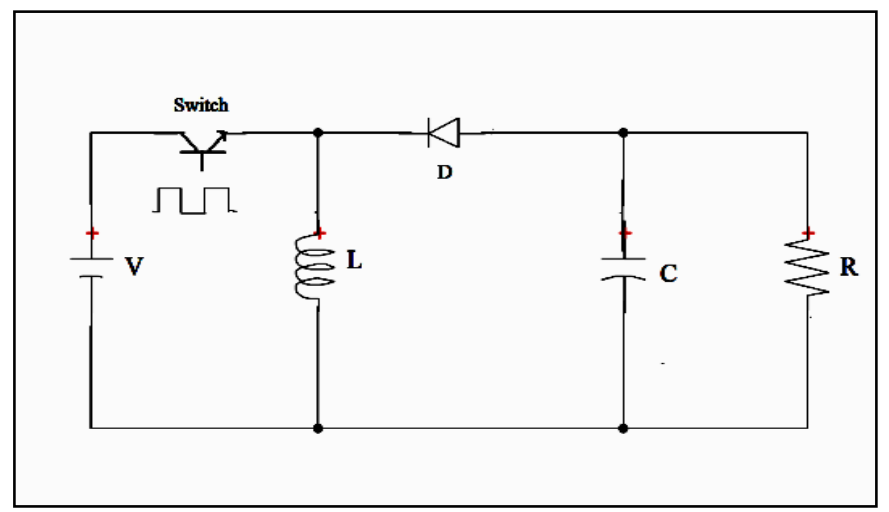

Fig. 4: DC-DC Buck-Boost Converter circuit scheme.

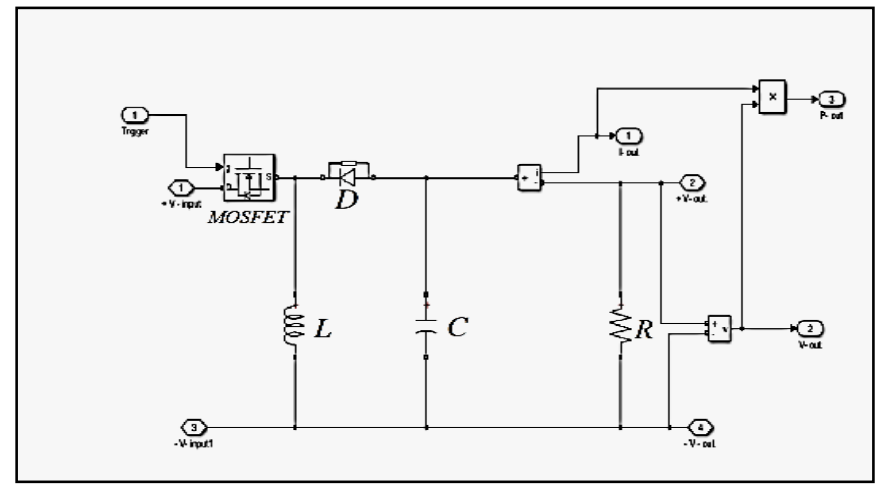

Fig. 5:The Buck-Boost converter Simulink model.

\section{The controller design}

Two control strategies are designed and simulated separately. These controllers determine the duty ratio for the switching device of the converter. These strategies are the proportional-integral-differential controller (PID) and the fuzzy logic control (FLC).

\section{1) The PID controller design}

The proportional-integral-differential controller has been designed to control the switching activity of the DC-DC buck-boost circuit. The parameters tuning can be achieved by Nichols -Ziegler method[18], and one of the newest metaheuristic algorithms called the Camel Travelling Algorithm(CTA)[19]. Fig. 6 shows the Simulink model of the PID controller.

2) The Fuzzy-Logic- Controller design (FLC):

In this paper, a PD-like fuzzy + I controller is designed. Fig. 7 illustrates controller construction[20]. The fuzzy part deals with the error proportional $e(t)$ with and the error derivative, which represents the change of error $\Delta e(t)$. Fig. 8 (a, b, and c) shows the e (t), $\Delta \mathrm{e}(\mathrm{t})$, and the output signal membership functions. Table I represents the rule table. $K_{p}, K_{i}$, and $K_{d}$ parameters are determined based on two methods, trial $\&$ error and the camel traveling algorithm (CTA). where $K_{p}$ and $K_{d}$ are considered as scaling or normalization factors for the fuzzy controller.

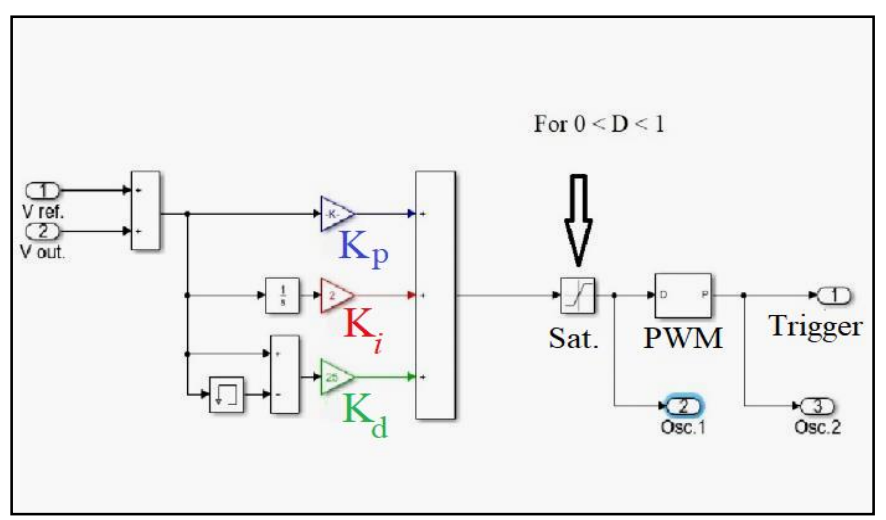

Fig. 6: PID controller Simulink model. 


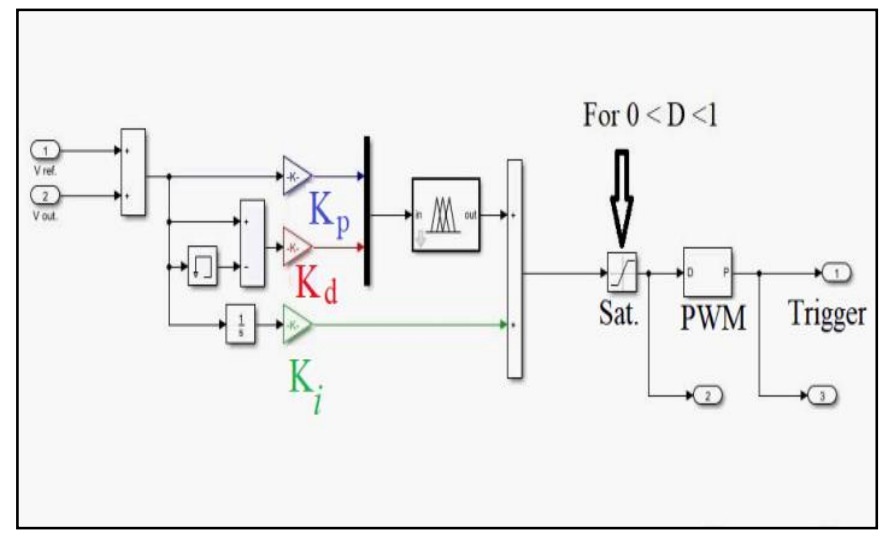

Fig. 7: The fuzzy logic controller Simulink model.

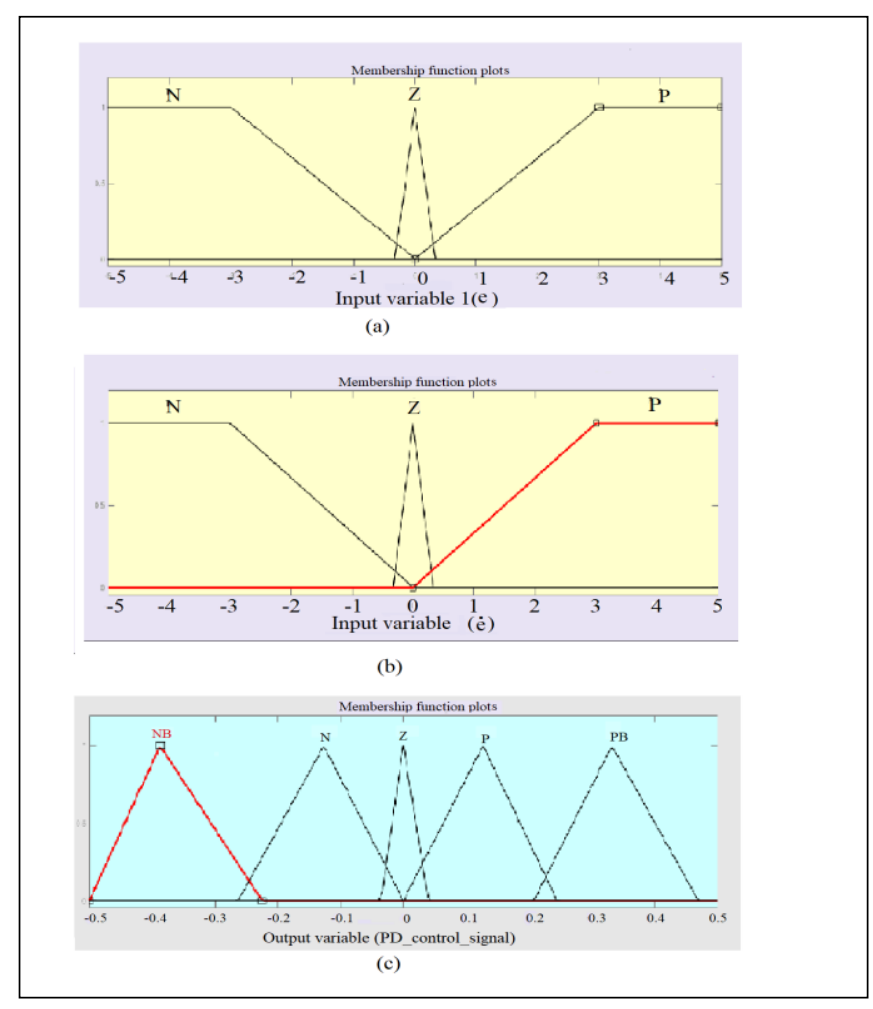

Fig. 8: The input and the output membership functions

TABLE I

THE RULE TABLE

\begin{tabular}{|c|c|c|c|}
\hline $\mathbf{e}$ & $\mathbf{P}$ & $\mathbf{Z}$ & $\mathbf{N}$ \\
\hline $\mathbf{P}$ & $\mathbf{P B}$ & $\mathbf{P}$ & $\mathbf{Z}$ \\
\hline $\mathrm{Z}$ & $\mathbf{P}$ & $\mathbf{Z}$ & $\mathbf{N}$ \\
\hline $\mathbf{N}$ & $\mathbf{Z}$ & $\mathbf{N}$ & $\mathbf{N B}$ \\
& & & \\
\hline
\end{tabular}

\section{SIMULATION RESULTS}

The proposed circuit is given in Fig. 9. The simulation results of this model can be summarized as:

\section{A. The PID parameters tuning and results}

Table II illustrates the results of the PID tuning parameters using the Nichols - Ziegler method[21]

\section{TABLE II}

PARAMETER VALUES ESTIMATED WITH NICHOLSZIEGLER

\begin{tabular}{|l|c|c|c|}
\hline Parameter & $\mathrm{K}_{\mathrm{p}}$ & $\mathrm{K}_{\mathrm{i}}$ & $\mathrm{K}_{\mathrm{d}}$ \\
\hline value & 0.016 & 1.29 & 0.0000126 \\
\hline
\end{tabular}

while Table III illustrates the results of the PID tuning parameters using the CTA.

TABLE III

PARAMETER VALUES ESTIMATED WITH CTA

\begin{tabular}{|l|c|c|c|}
\hline Parameter & $\mathrm{K}_{\mathrm{p}}$ & $\mathrm{K}_{\mathrm{i}}$ & $\mathrm{K}_{\mathrm{d}}$ \\
\hline value & 2.18 & 0.113 & 17.45 \\
\hline
\end{tabular}

The CTA based on the camel behavior when looking for the grassy region in the environment around the caravan travel path, updating its position until reaching the best region. Many factors have an influence on this process, such as the minimum and maximum limits of the camel position $\left(\boldsymbol{X}_{\min }\right.$ \&\& $\boldsymbol{X}_{\max }$.), the dimension of the environment $\boldsymbol{D}_{\boldsymbol{i}}$, the caravan size $\boldsymbol{N}$ (no. of camels), total journey steps looking for oases, the minimum and maximum temperature degree $\left(\boldsymbol{T}_{\min .} \& \boldsymbol{T}_{\max .}\right)$ and the visibility threshold $v$.

The factors values used in CTA are

$\left(X_{\min }=0\right.$,

$X_{\max }=5$,

$D_{i}=10$,

total journey steps $=1000$,

total No. of caravans $N=50$,

visibility threshold $v=0.1$,

$T_{\min .}=30$,

$T_{\max }=60$ ).

where,

$$
\begin{aligned}
& K_{p}=X_{\text {best }}(1) \\
& K_{i}=X_{\text {best }}(2) \\
& K_{d}=X_{\text {best }}(3)
\end{aligned}
$$




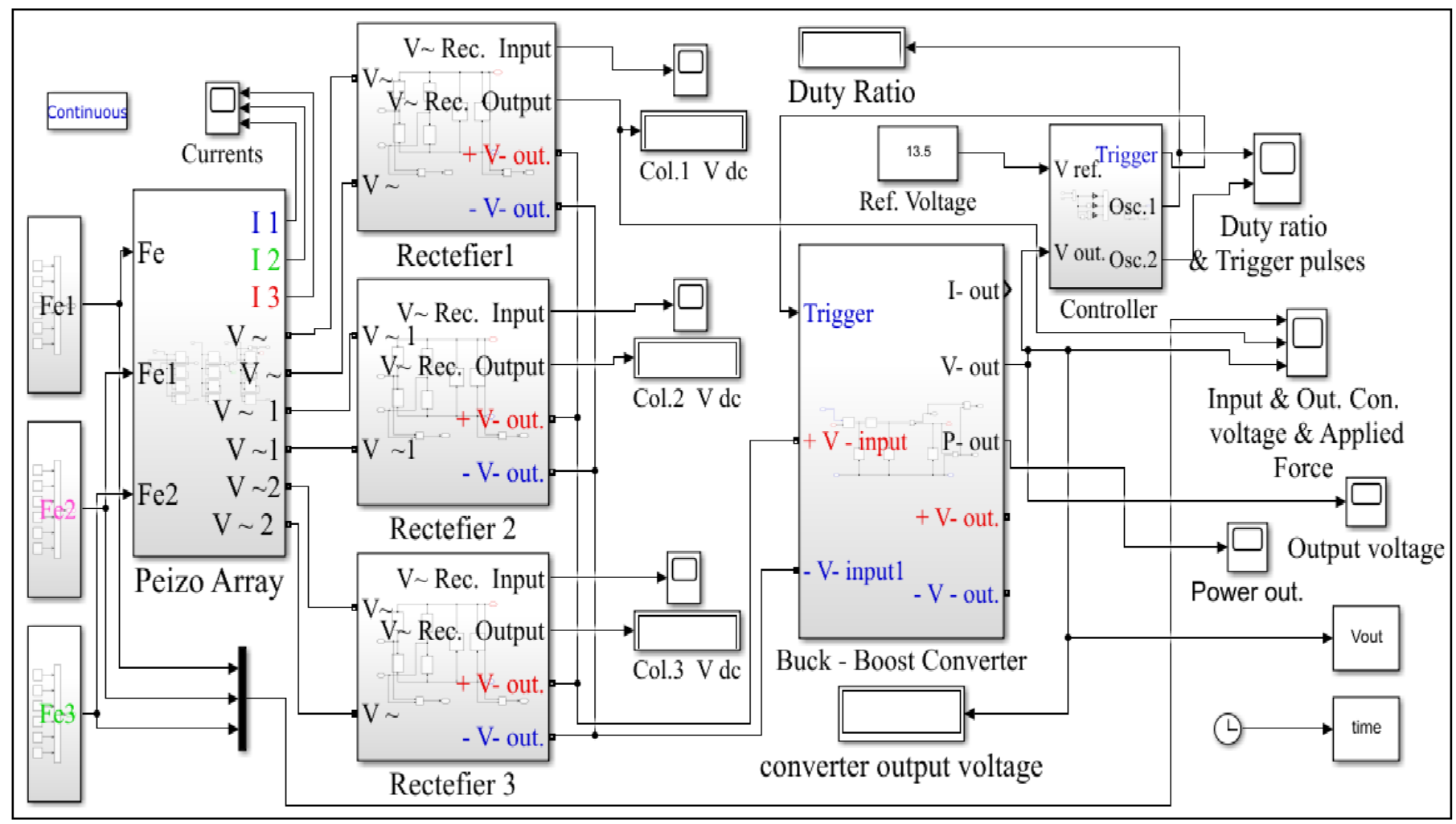

Fig. 9: The proposed circuit Simulink model

The simulation results for two different cases of the applied force can be summarized as :

\section{Case-1:}

By using ( $K_{p}, K_{i}$, and $K_{d}$ )values, which are estimated using the Nichols-Ziegler (NZ) method and the CTA, the system is tested under different operating conditions. Fig. 10 shows the converter response (output voltage) to the applied force with a short time spacing between force impulses. The difference in the converter behavior for the two cases under study can be observed clearly. Fig. 10(a) shows the applied force and input and output voltage of the converter using the PID controller using parameters estimated by Nichols- Ziegler method. Fig. 10(b) shows the same outputs using PID parameters optimized using the CTA.

The response of the converter is more stable when using CTA (see Fig. 10b) compared with the response by using NZ method (see Fig. 10a). There is no oscillation around set value when using CTA method.

Fig. 11 shows the rise time and the overshoot of the Converter response under PID control using parameters calculated by using: (a) NZ method. (b) CTA.

The response of the converter using the CTA faster than the $\mathrm{NZ}$, the rise time using CTA is $5.986 \times 10^{-4} \mathrm{sec}$. Moreover, by using the NZ, the rise time is $17 \times 10^{-4} \mathrm{sec}$. The overshoot is 1.9417 by using CTA and 1.9692 by using NZ method.
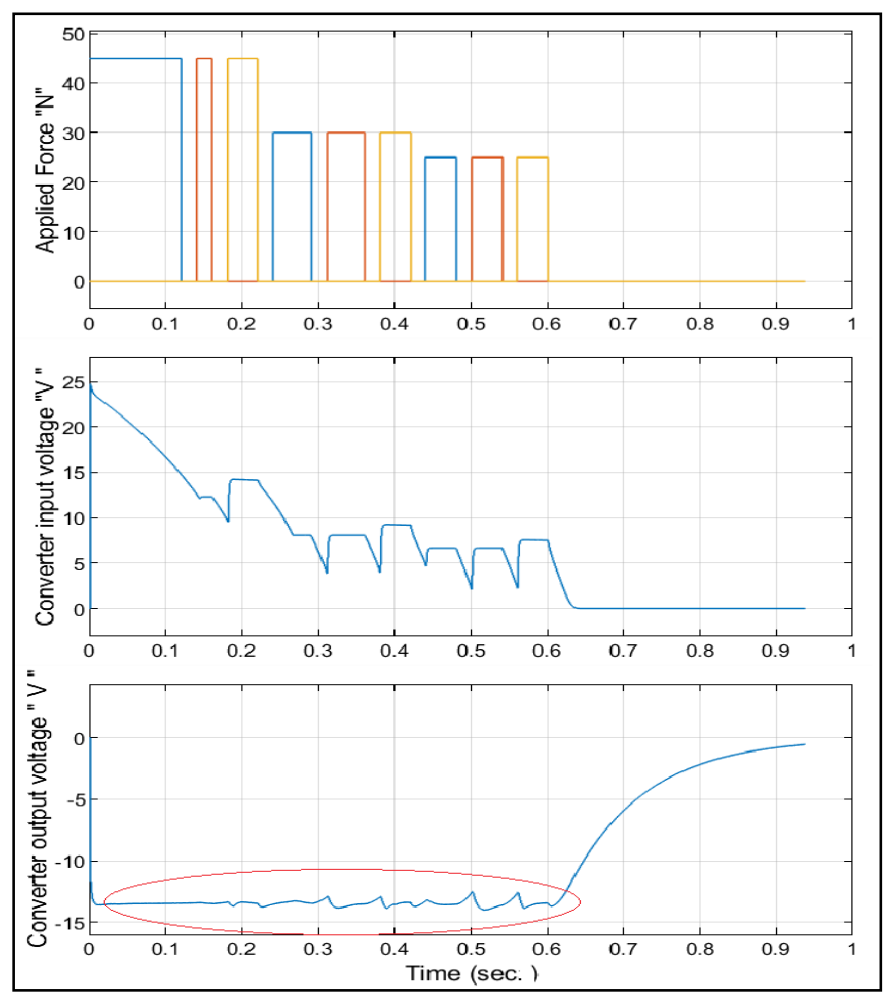

(a)

Fig. 10: Applied force(with short spacing time between impulses) and the Converter input and output voltage using PID controller parameters are calculated by : (a) NZ method (b) CTA method. 

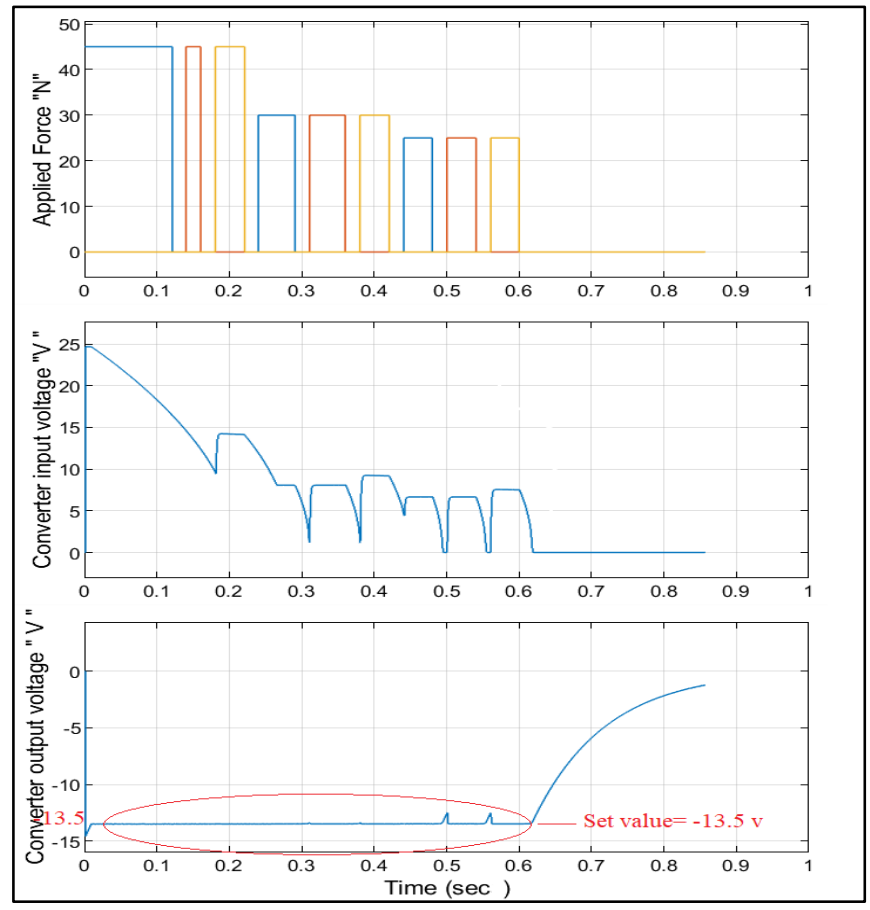

(b)

Fig. 10: Continued.

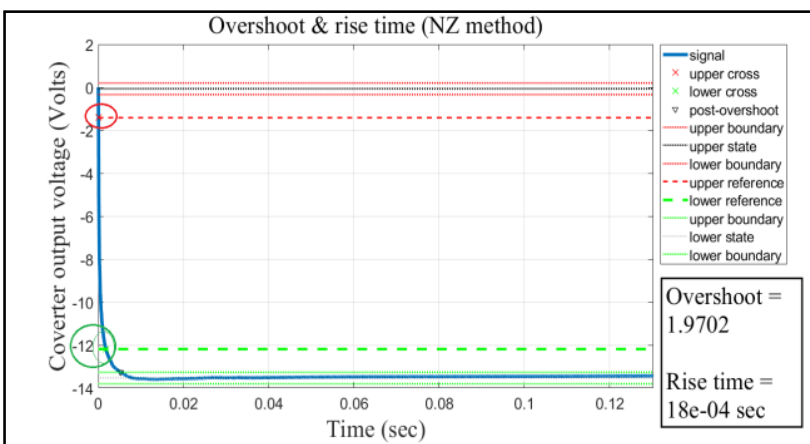

(a)

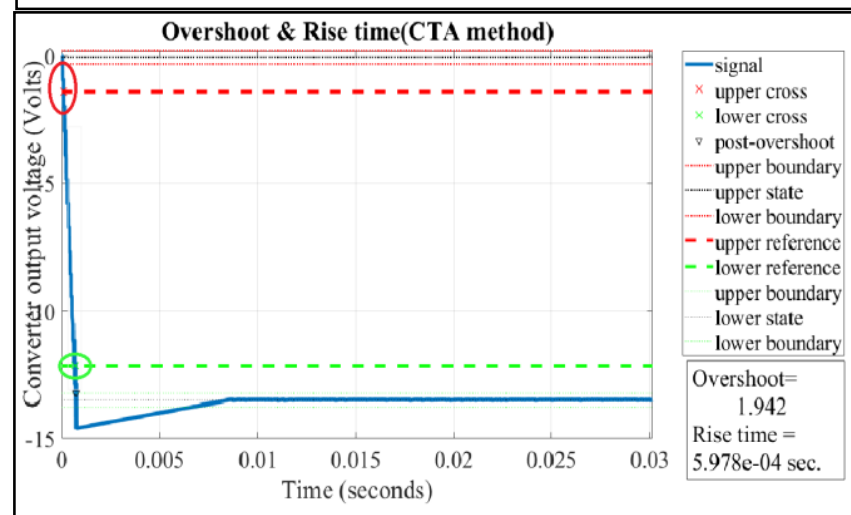

(b)

Fig. 11: The rise time and the overshoot of the output response when using (a) NZ method. (b) CTA method.

Case-2:

For the same parameters in case 1, but with more spacing time between the applied impulse forces. Fig. 12a shows the applied force output voltage, the converter input, and output voltages when using the PID controller, the parameters estimated using the NZ method.

Fig. 12b shows the applied force output voltage, the converter input, and output voltage when using the PID controller, the parameters estimated using the CTA method.

As shown in Fig. 12a, a spike will occur in the output voltage, and the PID controller takes a long time to return the converter output to the set value. While the response of the PID controller is very fast when using CTA method, and the output voltage will gain the set value fast, as shown in Fig. 12b.

Fig. 13 shows the rise time and the overshoot of the Converter response using; (a) NZ method, (b) CTA method. The overshoot of the converter using the CTA is less than the NZ method, the overshoot using CTA is 1.9622 at the beginning and 1.0561 at the time instant $0.4-\mathrm{sec}$ and by using the NZ, the overshoot is 2.0356 at the beginning and 32.88 at instant 0.4 sec. The rise time when using the CTA is better than that when using the NZ method.
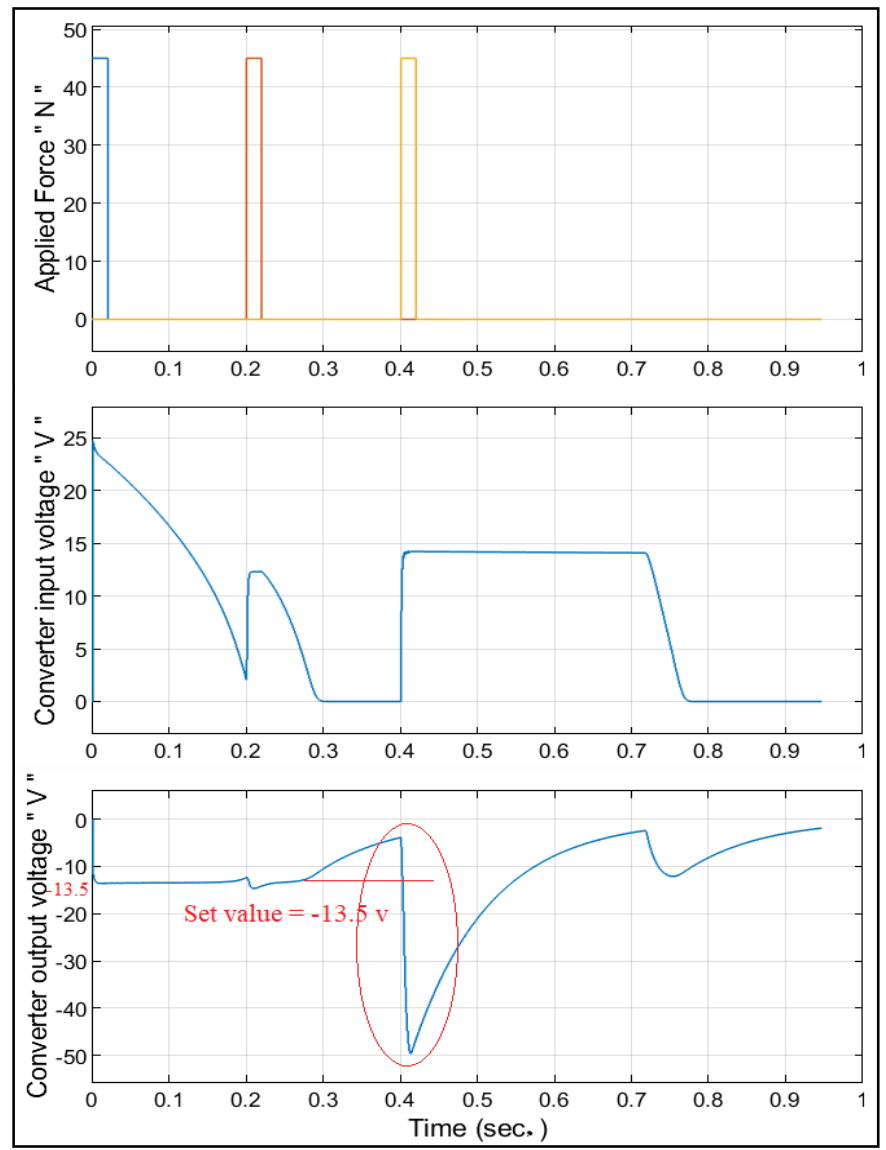

(a)

Fig. 12: Applied force(with more spacing time between impulses) and the Converter input and output voltage when PID parameters are calculated using: (a) the NZ method. (b) the CTA method. 

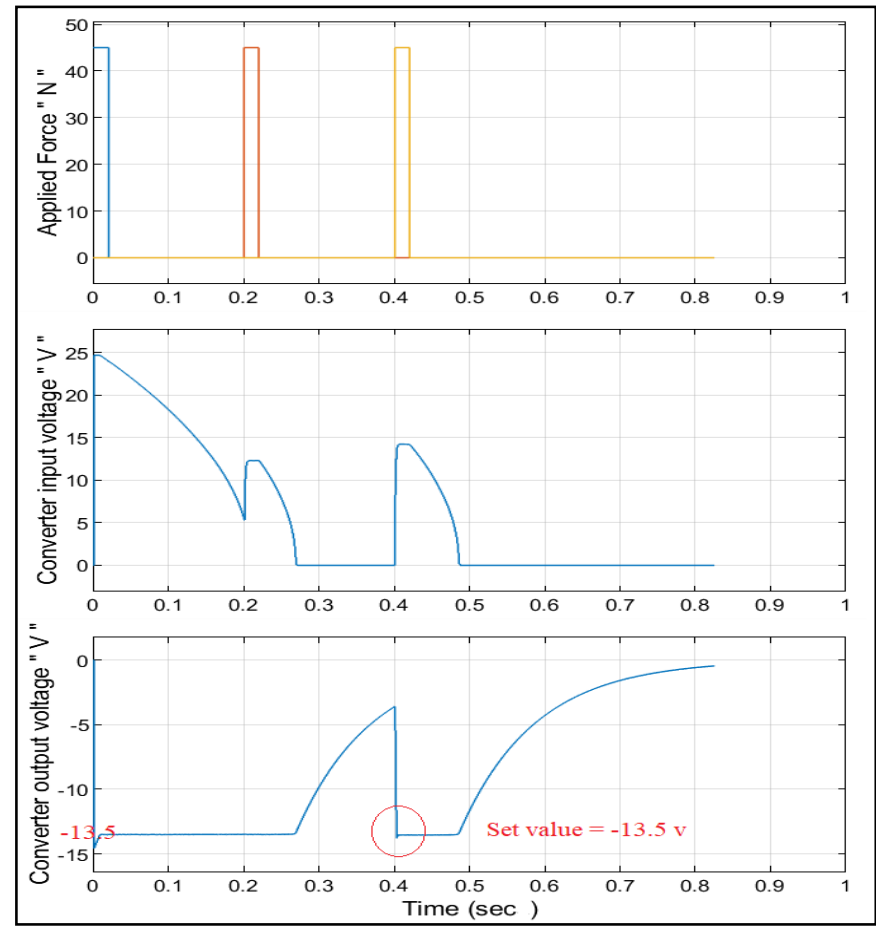

(b)

Fig. 12: Continued.
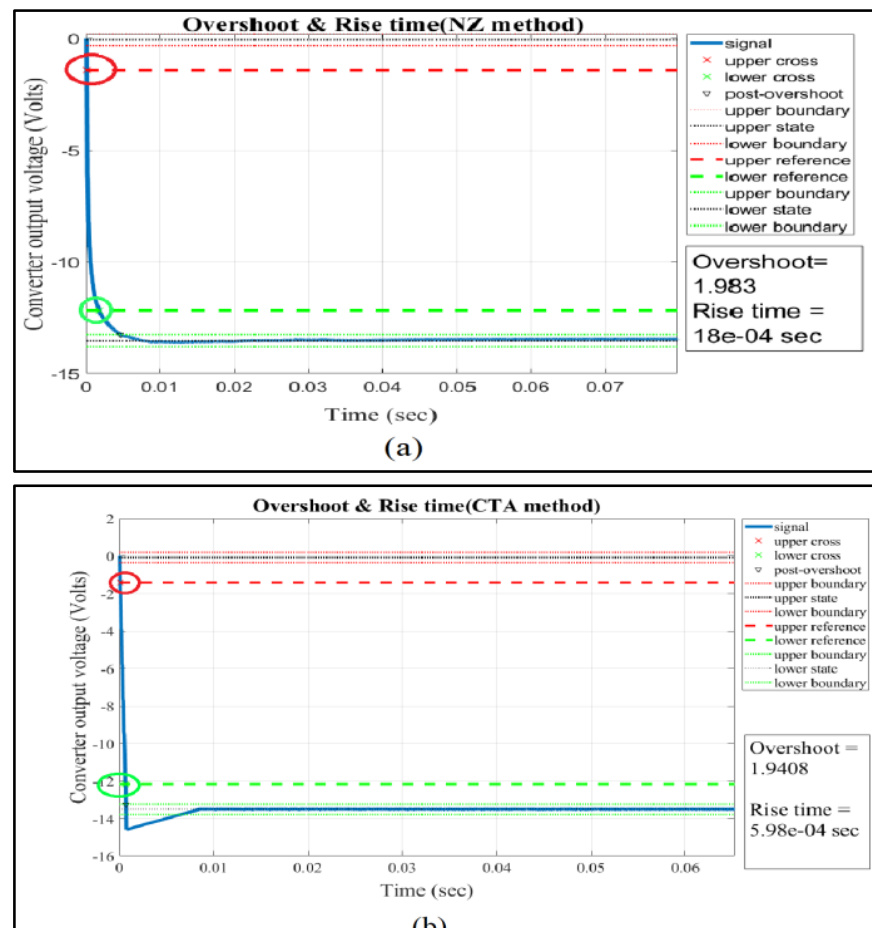

(b)

Fig. 13: The rise time and the overshoot of the output response when using (a) NZ method. (b) using CTA method.

\section{B. The fuzzy-controller parameters tuning and results}

Table IV illustrates the results of the fuzzy controller parameters using the trial \& error method.

\section{TABLE IV \\ PARAMETER VALUES ESTIMATED WITH TE}

\begin{tabular}{|c|c|c|c|}
\hline Parameter & $\mathrm{K}_{\mathrm{p}}$ & $\mathrm{K}_{\mathrm{i}}$ & $\mathrm{K}_{\mathrm{d}}$ \\
\hline value & 1.7 & 0.7 & 3 \\
\hline
\end{tabular}

while Table $\mathrm{V}$ illustrates the results of the PD like fuzzy $+\mathrm{I}$ controller tuning parameters using the CTA, which is the same listed in Table-3.

TABLE V

PARAMETER VALUES ESTIMATED WITH CTA

\begin{tabular}{|c|c|c|c|}
\hline Parameter & $\mathrm{K}_{\mathrm{p}}$ & $\mathrm{K}_{\mathrm{i}}$ & $\mathrm{K}_{\mathrm{d}}$ \\
\hline value & 2.18 & 0.113 & 17.45 \\
\hline
\end{tabular}

The results of the simulation of the proposed circuit with fuzzy controller under two cases of the applied force are:

Case-1:

In this case, the proposed circuit is examined under the influence of the applied force with the short spacing time between the force impulses using FLC and its parameters ( $K_{p}, K_{i}$, and $K_{d}$ ), which are estimated by using the two methods above.

Fig. 14 shows the applied force and the input and output voltage of the converter by using FLC parameters estimated by (a) trial and error(TE) method. (b) CTA method. The response of the converter using the FLC is nearly the same using the parameters which are estimated by the two methods above (TE \& CTA).

Fig. 15 shows the rise time and the overshoot of the converter output voltage by using FLC parameters calculated by (a) TE method. (b) CTA method. It is clear that the response is nearly the same for both, the overshoot is 1.832 when using TE method and 1.808 with CTA.

The rise time is $2.012 \mathrm{e}-04 \mathrm{sec}$ using TE method and the 2.011e-04 sec when using CTA method. 


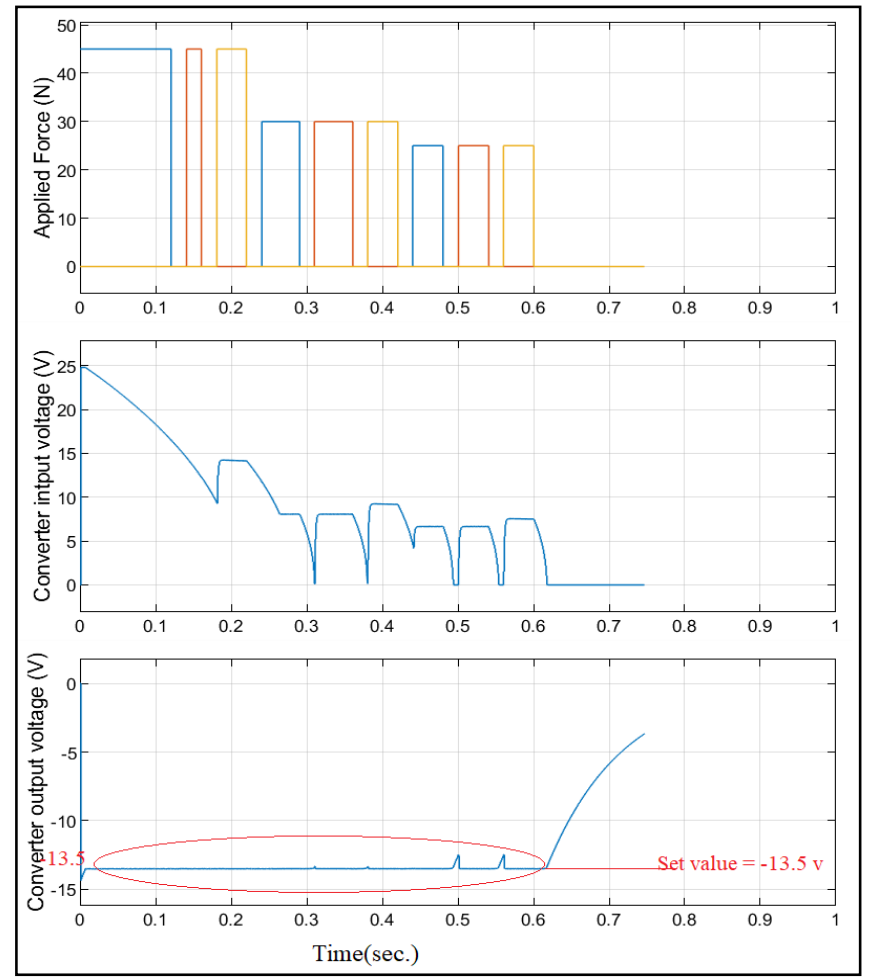

(a)

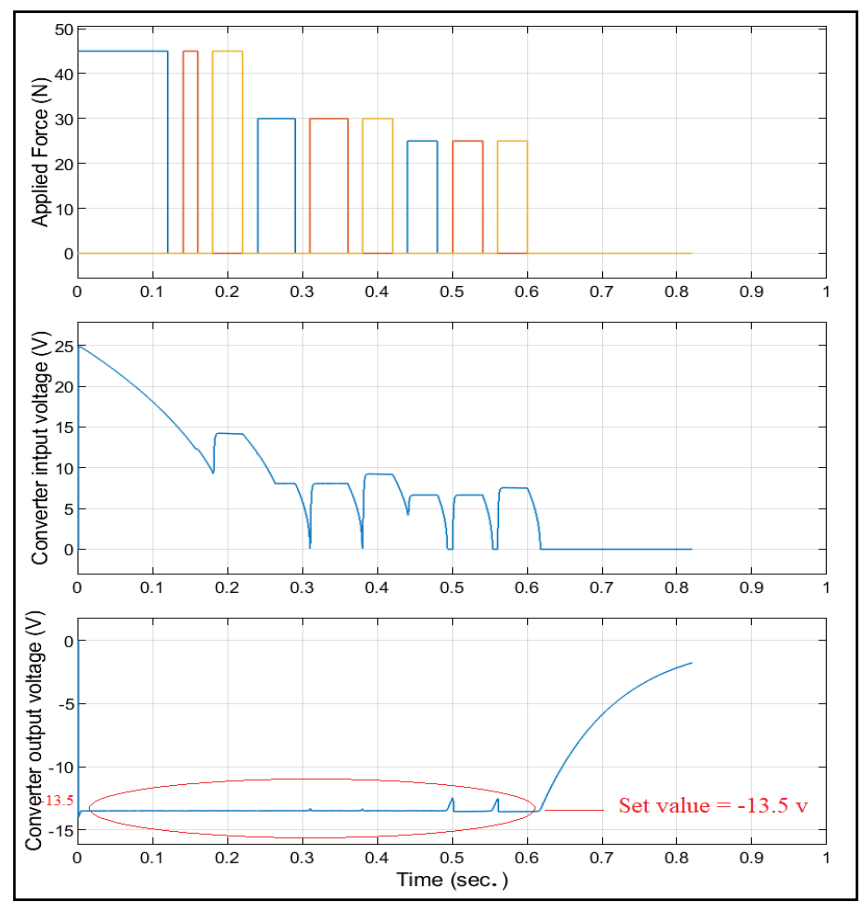

(b)

Fig. 14: Applied force(with short spacing time between impulses) and the Converter input and output voltage when FLC parameters are calculated using: (a) TE method. (b) CTA method.
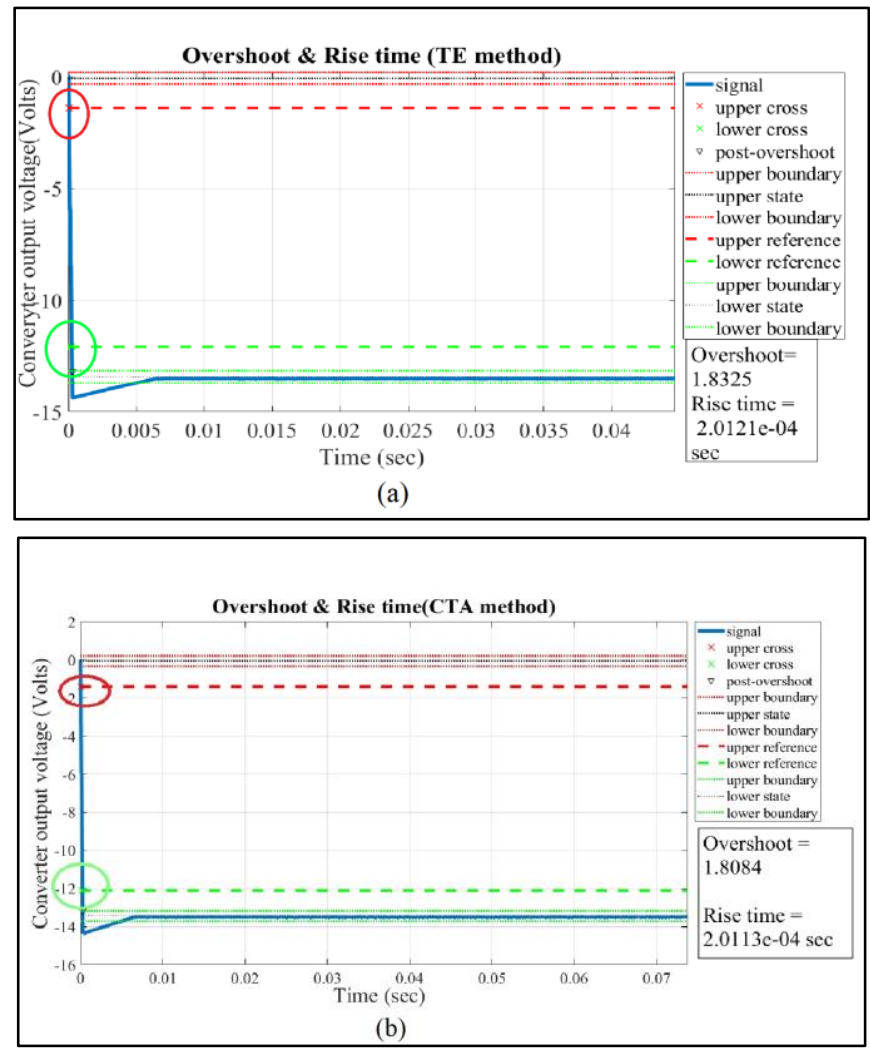

Fig. 15: The rise time and the overshoot of the output response when using FLC with parameters calculated by using (a) TE method. (b) CTA method.

Case-2:

With the same parameters used in case one but the applied force with more spacing between force impulses, as shown in Fig. 16.

Fig. 16a shows the applied force and the converter input and output voltage when using FLC with parameters estimated with TE method.

Fig. 16b shows the applied force and the converter input and output voltage using FLC, its parameters optimized with CTA method.

Slow converter output response under the control of FLC using parameters calculated by the TE method. It is clear from Fig. 16a, the spike occurs at 0.4-sec instant, and the converter takes a long time to return to the set value.

The response is very fast when using the parameters optimized by using the CTA method, and the output voltage returned to the set value fast, as shown in Fig. 16b

Fig. 17 shows the overshoot and the rise time of the converter response by using (a) TE method. (b) CTA method. 


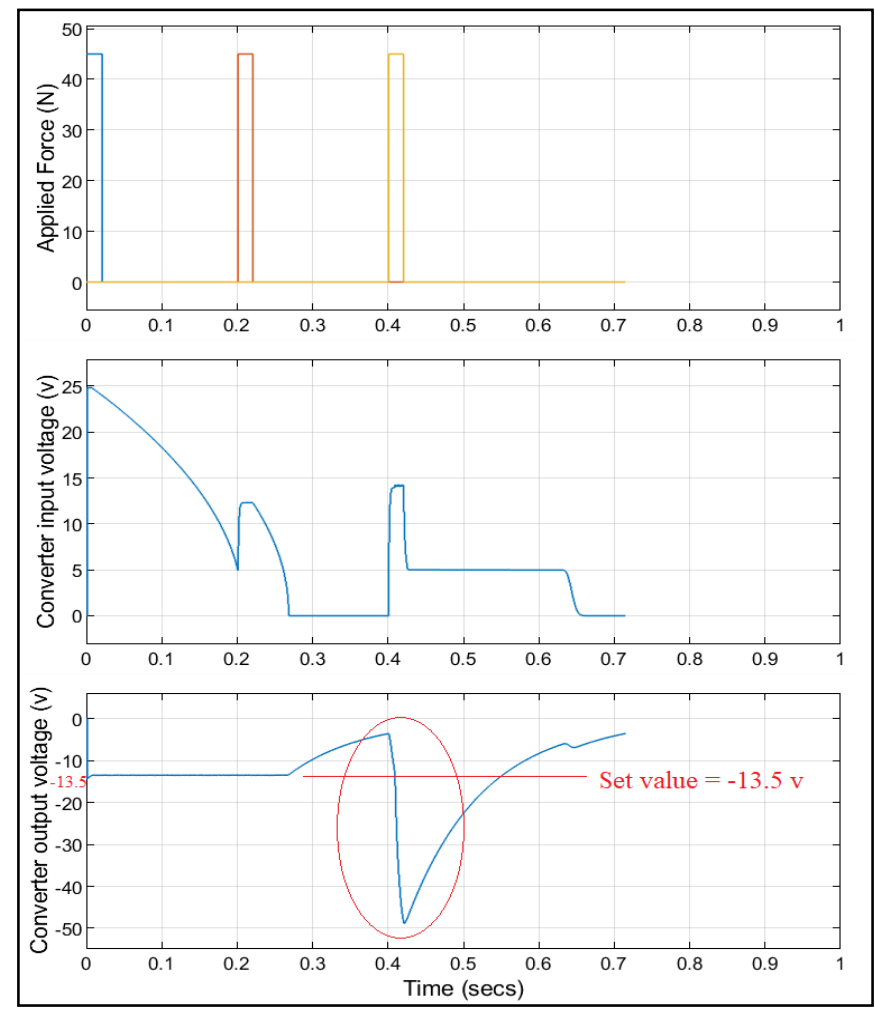

(a)

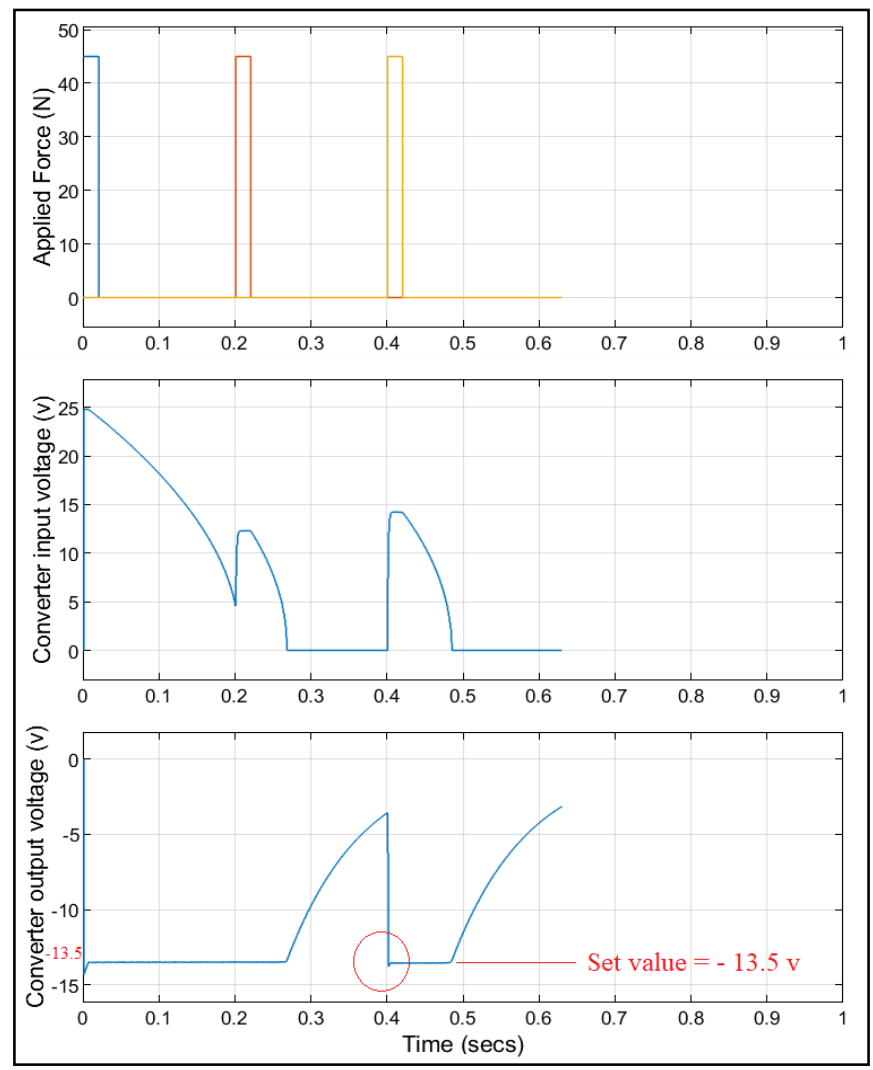

(b)

Fig. 16: Applied force(with more spacing time between impulses) and the Converter input and output voltage when FLC parameters are calculated using: (a) TE method (b) CTA method.

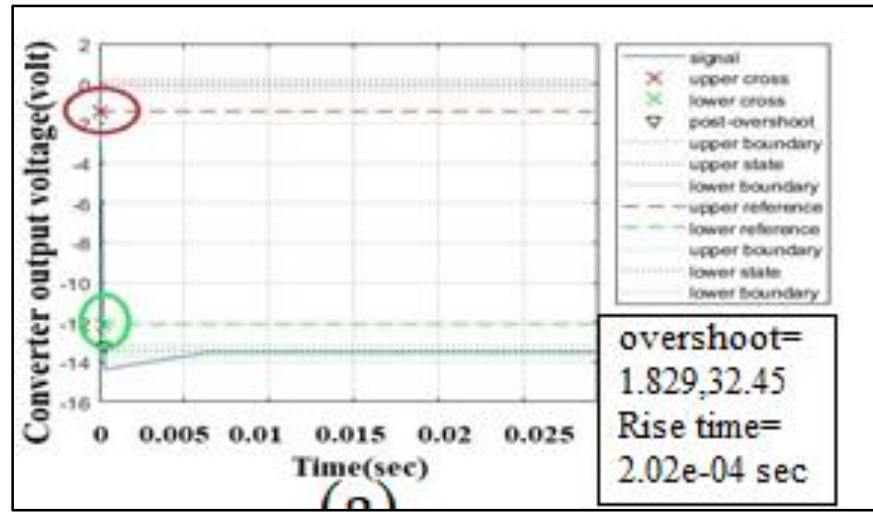

(a)

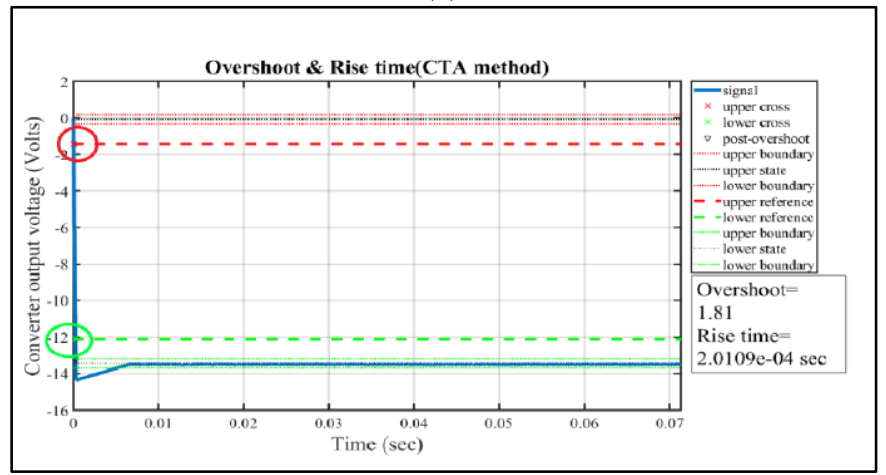

(b)

Fig. 17: The rise time and the overshoot of the output response when using FLC, its parameters calculated by using

(a) TE method. (b) CTA method.

\section{CONCLUSION}

The proposed model was tested under the influence of two different cases of the applied force, and the controller response was observed when applying the parameters obtained according to the Nichols-Ziegler, the trial and error, and the CTA methods. As a result, the optimization of parameters with (CTA) gives results better than the other method for both controllers in the short spacing and more spacing time between the applied force impulses to observe controllers behavior in sudden changes. The response of both controllers PID and FLC was very similar when using the parameters that were optimized using the CTA method, and this was very clear in the case of more spacing time between the impulses of the affecting force. The converter shows a good response when using these parameters.

\section{CONFLICT OF INTEREST}

The authors have no conflict of relevant interest to this article.

\section{REFERENCES}

[1] H. A. Sodano, G. Park, and D. J. Inman, "Estimation of Electric Charge Output for Piezoelectric Energy Harvesting," Strain, vol. 40, no. 2, pp. 49-58, 2004.

[2] S. P. Beeby, M. J. Tudor, and N. M. White, "Energy harvesting vibration sources for microsystems applications," Measurement Science and Technology, vol. 17 no.12, pp. R175-R195, 2006. 
[3] M. Pereyma, "Overview of the modern state of the vibration energy harvesting devices in Perspective technologies and methods in MEMS design," III international conference of young scientists, MEMSTECH, Piscataway, NJ., May 2007.

[4] S. R. Anton and H. A. Sodano, "A review of power harvesting using piezoelectric materials (2003-2006)," Smart Materials and Structures, vol. 16, no. 3, pp. R1-R21, 2007.

[5] S. Priya, "Advances in energy harvesting using low profile piezoelectric transducers," Journal of Electroceramics. Springer Science + Business Media, LLC, vol. 19, no. 1, pp. 167-184, 2007.

[6] K. A. Cook-Chennault, N. Thambi, and A. M. Sastry, "Powering MEMS portable devices - a review of non-regenerative and regenerative power supply systems with special emphasis on piezoelectric energy harvesting systems," Smart Materials and Structures, vol. 17, no. 4, pp. 1-33, 2008.

[7] S. Rafique, Piezoelectric Vibration Energy Harvesting and its Application to Vibration Control, University of Manchester , 2011.

[8] J. H. Pedersen, Low-Frequency Low Voltage Vibration Energy Harvesting Converter, Technical University of Denmark , 2011.

[9] Y. Wang and D. J. Inman, "A survey of control strategies for simultaneous vibration suppression and energy harvesting via piezo ceramic," Journal of Intelligent Material Systems and Structures, vol. 23, no. 18, pp. 2021-2037, 2012.

[10] A. H. Hosseinloo, T. L. Vu, and K. Turitsyn, “Optimal control strategies for efficient energy harvesting from ambient vibration," 54th IEEE Conference on Decision and Control (CDC), December 2015.

[11] N. Tsushima and W. Su, "Highly Flexible Piezoelectric Multifunctional Wings for Adaptive Vibration Control and
Energy Harvesting," 58th AIAA/ASCE/AHS/ASC Structures, Structural Dynamics, and Materials Conference. January, 2017.

[12] A. Erturk and D. J. Inman, Piezoelectric Energy Harvesting. $1^{\text {st }}$ ed. John Wiley \& Sons, Ltd., 2011, pp. 233-239.

[13]F. J. Holler, D.A. Skoog, and S. R. Crouch, Principles of Instrumental Analysis, $6^{\text {th }}$ ed. Cengage Learning, 2007, pp. 9.

[14] G. Gautschi, Piezoelectric Sensors: Force, Strain, Pressure, Acceleration, and Acoustic Emission Sensors, Materials, and Amplifiers, $1^{\text {st }}$ ed. Springer, 2002, pp. 87.

[15] IEEE Ultrasonic, Ferro-electrics, and Frequency Control Society, ANSI/IEEE Std. 176-1987, IEEE Standard on Piezoelectricity, 1987.

[16] V. R Kotdawala and V. N. Kamat, "Electromechanical Modeling and Simulation of Piezoelectric Energy Harvester using MATLAB SIMULINK," International Journal of Advanced Engineering and Research Development, vol. 5, no. 3, pp. 30-37, 2018

[17] D. W. Hart, Power Electronics, $1^{\text {st }}$ ed. McGraw-Hill, Inc., 2011, pp. 221-226.

[18] K. Ogata, Modern Control Engineering, $5^{\text {th }}$ ed. Pearson Education, Inc., 2010, pp. 570-577.

[19] R. S. Ali, F. M. Alnahwi, and A. S. Abdullah, "A modified camel traveling behavior algorithm for engineering applications," Australian Journal of Electrical and Electronics Engineering, vol. 16, no. 3, pp. 176-186, 2019.

[20] R. H. Thejel, Fuzzy logic based speed control of a multiphase series Connected multi-motor derive System Fed from SVPWM VSI, University of Basrah, 2008.

[21] M. Almawlawe and M. Kovandzic, "A modified method for tuning the PID controller for the Buck-Boost converter," International Journal of Advanced Engineering Research and Science (IJAERS), vol. 3, no. 12, pp. 20-26, 2016. 